\title{
Creative leaders create 'unsung heroes': leader creativity and subordinate organizational citizenship behavior
}

Xiao Deng and Zhishuang Guan ${ }^{*}$

\author{
* Correspondence: \\ guanzhishuang@163.com \\ Department of Organization \& \\ Strategic Management, Guanghua \\ School of Management, Peking \\ University, Haidian District, Beijing \\ 100871, China
}

\begin{abstract}
As leader creativity is found to be effective at promoting outcomes for organizations, more and more organizations select creative individuals as leaders. However, the influence of leader creativity has not received enough attention. Thus, this research seeks to focus on the potential influences of leader creativity in organizations. Based on social cognitive theory, we explore the relationship between leader creativity and subordinate organizational citizenship behavior (OCB). We find that leader creativity is positively related to subordinate OCB, and perceived team creative efficacy mediates the relationship. Moreover, creative self-efficacy moderates the relationships between perceived team creative efficacy and subordinate OCB. We then discuss implications and limitations, and suggest directions for future research.
\end{abstract}

Keywords: Creativity, Social cognitive theory, Human agency perspective, OCB, Efficacy

\section{Introduction}

A survey of 1500 chief executives conducted by IBM's Institute for Business Value shows that CEOs identify "creativity" as the most important leadership competency for the successful organizations of the future (Kern, 2010). Past research also shows that leaders with creative abilities are more effective at promoting positive change and encouraging subordinates (Mueller, Goncalo, \& Kamdar, 2011). As a result of the increasing importance of leader creativity, a growing number of creative individuals are being selected as leaders. More scholarship is also being devoted to how subordinates perceive and react to creative leaders.

It is interesting that scholarly research on the impact of leader creativity has focused almost exclusively on individual creativity, and as a result, has not paid as much attention to other possible and important outcome behaviors (Huang, Krasikova, Liu, 2016). Based on our observations, in teams with creative leaders, instead of all members becoming more creative, many team members will do their best to support and help the team and team leaders to achieve the team's creative goals. According to the literature, the behaviors that subordinates engage in to support and benefit the organization are referred to as organizational citizenship behavior (OCB). OCB is an extra-role behavior but very necessary for an organization's success (Niehoff, 1993). As such, we investigate one potential reaction of subordinates to creative leaders- engaging in actions that

(c) The Author(s). 2017 Open Access This article is distributed under the terms of the Creative Commons Attribution 4.0 International License (http://creativecommons.org/licenses/by/4.0/), which permits unrestricted use, distribution, and reproduction in any medium, provided you give appropriate credit to the original author(s) and the source, provide a link to the Creative Commons license, and indicate if changes were made. 
support and benefit the organization and its members. As we see in numerous Hollywood movies: whenever there is a superhero making the biggest difference, there are many unsung heroes supporting him/her quietly.

According to social cognitive theory as developed by Bandura in 1986, social environments can influence individual behavior through shaping individual cognition. Efficacy, which refers to people's confidence in their capabilities to carry out tasks well, has been proposed as an important cognitive factor that can be affected by social environments as well as influence continuous behaviors. Team creative efficacy refers to members' belief in their team's capabilities to successfully perform creativity (Shin \& Zhou, 2007). This belief is supported through important social cues such as how team leaders and influential employees behave. Therefore, we choose team creative efficacy as the mechanism of how a leader's creativity influences employees' OCB. Also, we try to shed light on when a creative leader influences a subordinate's OCB. Consistent with social cognitive theory, we propose that a subordinate's creative self-efficacy may make the difference.

In this paper, we make several important contributions to the literature. Firstly, our novel framework contributes to a burgeoning body of literature that demonstrates how a leader's creativity can also influence other employee behaviors, which in this paper refers to OCB. Given the concurrent popularity of creative leaders and employee OCB, this represents an important step toward reducing a critical theory divide.

Secondly, in addition to understanding the influences of a creative leader on employees' OCB, we attempt to shed light on the theoretical mechanisms from the subordinate's perspective. Most previous research explores the influence of creative leaders on subordinates through the leader's actions and perspective. On the contrary, we emphasize how subordinates perceive the leader's creativity. Specifically, consistent with social cognitive theory, we argue that the subordinate's perceived team creative efficacy will mediate the effect of a creative leader on an employee's OCB.

Thirdly, we also try to clarify when the leader's creativity will impact a subordinate's OCB. Based on social cognitive theory, we posit that perceived low creative self-efficacy will lead an employee to try methods other that creativity to contribute to the whole team, which in turn will accentuate the effect of a creative leader on employee OCB.

In the following sections, we first review the literature on creativity and social cognitive theory. Then we develop a conceptual framework that accounts for whether subordinates may engage in $\mathrm{OCB}$ when facing creative leaders and why leader creativity motives subordinates to engage in OCB. In particular, we identify a mediator (team creative efficacy) and a moderator (creative self-efficacy) of the relationship between leader creativity and subordinate OCB. Next we test this model through 2 studies. Study 1 uses a survey method with a sample of 39 teams, consisting in total of $153 \mathrm{MBA}$ and undergraduate students; Study 2 uses a between-subject factorial design experiment with a sample of 70 working employees recruited through Amazon MTurk (www.mturk.com). Finally, we discuss the implications and limitations of this research.

\section{Theoretical background}

\section{Leader creativity and employee OCB}

Creativity refers to the ability to produce ideas that are novel (e.g. original and unexpected) and appropriate (e.g. useful and suitable for the situation) (Amabile, 1983, 1988). 
Since people recognize the importance of creativity and are interested in increasing creativity, more and more creative people are being recruited and are appearing in workplaces especially as leaders. However, little attention has been paid to this growing phenomenon. Huang, Krasikova and Liu (2016) find that leaders with higher creative efficacy are more likely to improve employees' creativity through encouraging them. Nevertheless, they investigate this issue from the perspective of the leader and only focus on subordinates' creativity as the outcome. As the leader's actions are an important cue for subordinates to construct their cognition about the team, we explore the influences of leader creativity on subordinates from the perspective of the subordinate.

OCB was introduced by Organ and his colleagues over thirty years ago (Bateman \& Organ, 1983). Since then, researchers have extended their work to further investigate this construct, and one of the most researched aspects is the antecedents of OCB. Empirical research has focused on four major categories of antecedents: employee characteristics (e.g. employee attitudes and dispositions, general mental ability and political skills), task characteristics (e.g. task feedback, task routinization and job insecurity), organizational characteristics (e.g. organizational formalization and cohesion, interactional fairness and organizational constraints), and leadership behaviors (e.g. transformational leadership, leader-member exchange, emotional expressions of leaders and supervisor mentoring) (Podsakoff, MacKenzie, Paine, \& Bachrach, 2000; Britt et al., 2012; Gonzalez-Mule, Mount \& Oh, 2014; Koning \& Kleef, 2015; Eby, Butts, Hoffman \& Sauer, 2015; Lam, Liang, Ashford \& Lee, 2015; Matta, Scott, Koopman \& Conlon, 2015; Badawy, Shaughnessy, Brouer \& Seitz, 2016; Collins \& Mossholder, 2017).

In our research, we mainly focus on the effects of the creative behaviors of leaders on $\mathrm{OCB}$, as OCB is important for organizations and leader behavior has been shown to play a key role in influencing OCB (Podsakoff et al., 2000). When subordinates realize their leader is creative, they may feel more confidence and identify more closely with their leader. Thus subordinates may be more motivated to follow and rely on their leader, and to support their leader when needed. Leaders provide the social cues for subordinates to form their perception of team capabilities. When leaders are very creative, subordinates are inclined to be more confident in the creativity of the team. Therefore, subordinates are motivated to stay with the team when confronted with challenges and put in effort for the team when they need to achieve team goals. Subordinates will engage in more supporting behaviors to benefit the team and attain team goals. Therefore, we propose that when leaders are creative, subordinates will engage in more supporting behaviors for not only the leader but also the team, which can be defined as OCB. To summarize, these arguments yield the following hypothesis:

Hypothesis 1: Leader creativity is positively related to OCB.

\section{Team creative efficacy as a moderator}

In social cognitive theory, Bandura put forth the process of triadic interaction between behavior, cognition and environment (Bandura, 1986). Three aspects are key in this process: mastery modeling, the cultivation of people's beliefs in their capabilities, and people's motivation through goal systems (Bandura, 1986). Efficacy, referring to people's beliefs in their capabilities to mobilize the motivation, cognitive resources, and courses 
of action needed to exercise control over events in their lives, is a key concept in social cognitive theory (Bandura, 1989). According to Bandura, people develop a sense of efficacy based on social information, and their sense of efficacy will impact their ability to perform. Taken together, people's sense of efficacy plays a mediating role between the social environment and their behavior.

Further, people may have difference perceptions of their self-efficacy in different domains. Bandura (1986) noted that self-efficacy specific to a given activity domain was most instrumental in predicting performance in that domain. In the creativity domain, creative self-efficacy is defined as the self-view that one has the ability to produce creative outcomes (Tierney \& Farmer, 2002). Similarly, at the team level, perceived team efficacy serves functions similar to those of personal efficacy beliefs and operates through similar processes (Bandura, 1997). At the team level, team creative efficacy is about the members' beliefs in their teams' capabilities of producing creative ideas (Shin \& Zhou, 2007). According to social cognitive theory, since leaders have the most agency in their team to some degree, when leaders are very creative, subordinates may think their teams are very competitive in the creative domain and become confident in team creativity. As a result, subordinates' perceived team creative efficacy will rise.

As noted by Bandura, perceived high team creative efficacy can increase subordinates' motivation to pursue a team's shared creative goals and pushes them to make more efforts and be more persistent. OCB is one way for them to pursue their team's creative goal through supporting the leader and the whole team. Thus, subordinates with high team creative efficacy would like to perform more OCB to contribute to goal achievement compared with those with low team creative efficacy.

To sum up, when subordinates think their leaders are very creative, since the leader provides some of the most important social cues for subordinates, subordinates will consider their teams to be very good at creativity and capable of achieving creative goals. As a result, the team creative efficacy of subordinates will increase. With increased team creative efficacy, subordinates will have more motivation to put effort into their work, such as supporting the team, to pursue creative goals. Thus, subordinates' OCB will increase. Therefore, here we propose the following hypotheses:

Hypothesis 2: Team creative efficacy mediates the positive relationship between leader creativity and subordinates' OCB.

\section{Creative self-efficacy as a moderator}

When subordinates' team creative efficacy is high, they are motivated to achieve team creative goals. However, since what they can contribute to the team's creative goals is varying, how much effort they will put into OCB depends on themselves. Their creative self-efficacies can be the basis for them to make judgments on which behaviors they are more interested in (Bandura, 2001). Subordinates' creative self-efficacy refers to their belief in their own creative abilities, which may impact their motivation and efforts to be directly creative. For those who are not confident in their own creativity, if they want the team to produce the expected team creative outcomes, a realistic way for them to contribute is to support others, on whom they can rely to be directly creative. Thus, they tend to perform more OCB. That is to say, subordinates whose creative 
self-efficacy is low while team creative efficacy is high, are more inclined to engage in team supporting work such as OCB to make up for the fact that they themselves cannot achieve the desired goals. To the contrary, subordinates with high creative self-efficacy and high team creative efficacy may have more choices in achieving the team creative goals, and thus may perform less OCB. Therefore, we test the following predictions:

Hypothesis 3: Subordinates' perceived creative self-efficacy moderates the relationship between team creative efficacy and subordinates' OCB in such a way that when perceived creative self-efficacy is low the positive relationship between team creative efficacy and subordinates' OCB becomes stronger.

The conceptual model is presented in Fig. 1.

\section{Study 1}

Method

\section{Research setting, participants, and procedure}

Participants in this study were MBA and undergraduate students from a university in northeastern China. The MBA students $(N=71)$ were in a course on new venture development and the undergraduate students $(N=82)$ were in a course on innovation management. The same professor taught these two classes in the same semester. To help students learn and simulate the process of innovation and entrepreneurship, the professor required these two classes to work on two team projects on new venture business plan development, which involved the exploration of customers' demands, generation of new ideas for products or services, in-depth analysis of markets, prediction of the future and so on. The professor repeatedly emphasized the importance of creativity throughout the process. The deliverables included a final report and an in-class presentation, which counted for a major portion of the course grade. Students formed study teams ranging from three to six members and each team selected a team leader.

With the approval of the professor, we obtained the emails and team membership information of all the students. We contacted them before their first project to explain the purpose of the survey and guarantee the voluntary nature of participation and data

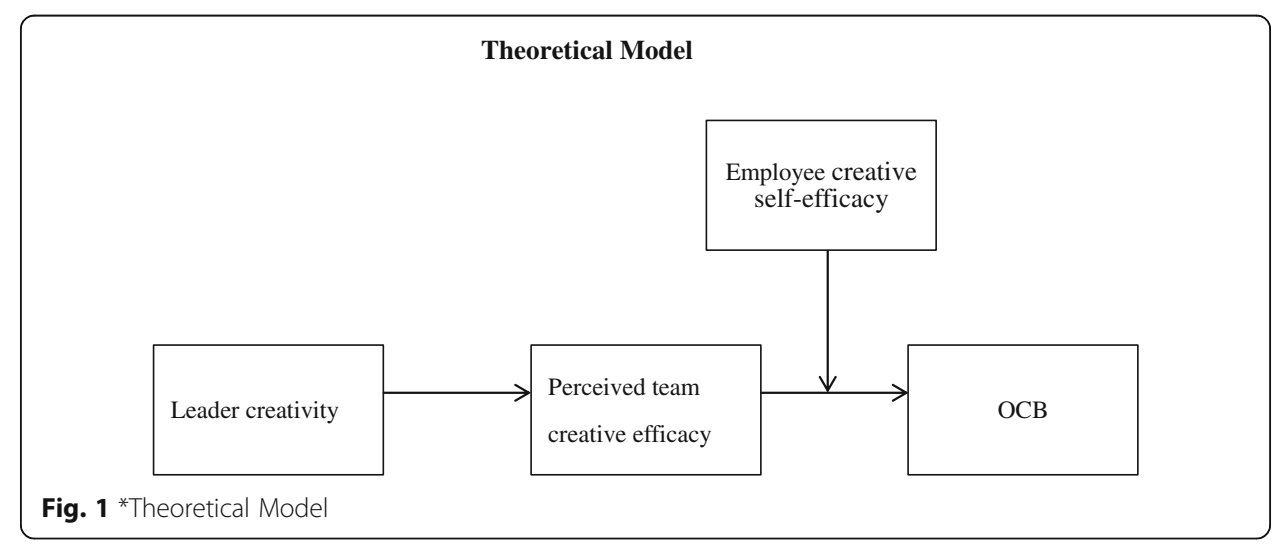


confidentiality. We then distributed the online questionnaires twice. After the first team project was completed in the sixth week of the course, we sent out the first survey to all team members excluding the team leaders to measure leader creativity, perceived team creative efficacy, creative self-efficacy and controlled variables. The second time was six weeks later. After the last class we sent out the second online questionnaire to team leaders who rated each member in their team on OCB.

The final samples included 114 team members and 39 team leaders, with 20 teams for the undergraduate class and 19 teams for the MBA class. The team size ranged from three to six students. Females accounted for $62.3 \%$ of the respondents. $47 \%$ of the total are MBA students.

\section{Measurement}

All our measures had been previously validated in Chinese organizations. We translated all scales into Chinese by following the translation and back translation procedures suggested by Brislin (1986) to minimize translation errors. Unless otherwise indicated, all the variables were measured by asking participants to rate the question on a sevenpoint Likert-type scale ranging from 1 = "strongly disagree" to 7 = "strongly agree".

Leader creativity We used the 13-item scale developed by Zhou and George (2001). Sample items are "My team leader suggests new ways to achieve goals or objectives", "My team leader often has a fresh approach to problems", "My leader often has new and innovative ideas", "My team leader is a good source of creative ideas" (Zhou \& George, 2001). The index score was calculated by taking the average of the 8 items (Cronbach's $\alpha=0.97$ ).

Perceived team creative efficacy We used the three-item scale developed by Zhou and Shin (2007). Sample items are "I feel my team is good at generating novel ideas " and "I have confidence in the ability of my team to solve problems creatively." The index score was calculated by taking the average of the three items (Cronbach's $\alpha=0.93)$.

OCB We adopted the 13-item scale developed by Williams and Anderson (1991). Sample items are: "I will give advance notice when unable to come to work," "I will take undeserved work breaks." The index score was calculated by taking the average of the three items (Cronbach's $\alpha=0.71$ ).

Creative self-efficacy Creative self-efficacy was measured by three items adapted from Tiernery and Farmer(2002). Examples included "I feel I am good at generating novel ideas" and "I have confidence in my ability to solve problems creatively." Responses were also made on a 7-point scale ranging from "strongly disagree" to "strongly agree." The Cronbach's alpha for this scale was 0.80 .

Controls Control variables included the team members' demographic information such as gender ( 0 " = female, " 1 " = male), education ( 1 " = undergraduate students, "2" = graduate student, "3" = Ph.D. student). Previous research found that both gender and education may influence employees' OCB (Beauregard, 2012; Lev \& Koslowsky, 
2012). The difference in team size is an important factor that needed to be taken into consideration due to team interaction; therefore, team size was also controlled for.

\section{Results}

The means, standard deviations, and bivariate correlations for all the variables are shown in Table 1. It is noteworthy that the leader's creativity is significantly and positively correlated with both team creative efficacy and OCB.

To test our hypotheses, we conducted data analyses in four steps. In Step 1, we entered the control variables. In Step 2, we used OLS models to examine the main effects of leader creativity and OCB. In Step 3, we employed Baron and Kenny's (1986) threestep mediation process to investigate the mediation effects of perceived team creative efficacy. In Step 4, we entered the interaction terms including creative self-efficacy to test Hypotheses 3. Table 2 summarizes the results of the regression analyses for testing the four hypotheses. We also tested our results using simple slope analysis(Aiken, West, \& Reno, 1991).

\section{Leader creativity and $O C B$}

Hypothesis 1 predicted a positive relationship between leader creativity as evaluated by team members and employee OCB. Table 2 presents the results of our analyses. As shown in Model 4, the positive effect of leader creativity on OCB is significant $(\beta=0.296, p<.01)$. Thus, Hypothesis 1 is supported.

\section{Team creative efficacy as the mediator}

Hypothesis 2 predicted that perceived team creative efficacy can mediate the positive relationship between leader creativity as perceived by team members and OCB. We followed Baron and Kenny's (1986) mediation process. Hypothesis 1 passed the first step of Baron and Kenny's (1986) mediation process. For the following three steps, in Step 1, we found that perceived leader creativity is significantly related to perceived team creative efficacy $(\gamma=0.694, p<.01)$. In Step 2, perceived team creative efficacy was found to be significantly related to OCB $(\gamma=0.276, p<0.1)$. For Step 3, when we added the perceived team creative efficacy into Model 4, as shown in Model 6, leader creativity was no longer significantly related to OCB while team creative efficacy is significantly related to $\operatorname{OCB}(\gamma=0.188, p<0.1)$, which meant that perceived team creative efficacy fully mediates the relationship between leader creativity and employee OCB.

Table 1 *Means, standard deviations, and intercorrelations of variables in Study 1

\begin{tabular}{llllllllll}
\hline Variable & Mean & SD & 1 & 2 & 3 & 4 & 5 & 6 & 7 \\
\hline 1. Gender & 0.377 & 0.487 & & & & & & & 8 \\
2. Education & 1.553 & 0.680 & -0.031 & & & & & & \\
3. Team size & 3.446 & 2.00 & 0.176 & -0.12 & & & & & \\
4. Leader age & 25.07 & 5.90 & 0.163 & -0.02 & -0.085 & & & & \\
5. Leader creativity & 5.479 & 0.928 & 0.001 & -0.093 & -0.011 & 0.117 & & & \\
$\begin{array}{l}\text { 6. Perceived team } \\
\text { creative efficacy }\end{array}$ & 5.543 & 0.982 & -0.007 & -0.012 & -0.043 & -0.091 & $0.624^{* *}$ & & \\
$\begin{array}{l}\text { 7. Creative self-efficacy } \\
\text { 8. OCB }\end{array}$ & 5.210 & 0.961 & 0.207 & $-0.257^{* *}$ & -0.048 & 0.041 & 0.128 & $0.249^{* *}$ & \\
\hline
\end{tabular}

Note. $N=114 .{ }^{*} p<.05,{ }^{* *} p<.01,+<.10$ 
Table 2 *Results of hierarchical regression analysis

\begin{tabular}{|c|c|c|c|c|c|c|c|c|}
\hline Independent variables & $\begin{array}{l}\text { Team cre } \\
\text { efficacy }\end{array}$ & ative & OCB & & & & & \\
\hline Main effects & Model 1 & Model 2 & Model3 & Model 4 & Model 5 & Model 6 & Model 7 & Model 8 \\
\hline Gender & -0.435 & 0.016 & -0.435 & $-0.433^{* *}$ & $-0.418^{*}$ & -0.436 & -0.465 & -0.417 \\
\hline Education & -0.907 & 0.109 & -0.907 & -0.052 & -0.083 & -0.072 & -0.042 & -0.034 \\
\hline Team size & -0.021 & -0.024 & $-0.021^{*}$ & -0.021 & -0.016 & -0.016 & -0.016 & -0.020 \\
\hline Leader age & 0.017 & $-0.031^{* *}$ & $0.017^{*}$ & 0.011 & 0.021 & 0.017 & 0.015 & 0.016 \\
\hline Leader creativity & & $0.694^{* *}$ & & $0.296^{* *}$ & & 0.165 & 0.174 & 0.276 \\
\hline Team creative efficacy & & & & & $0.276+$ & $0.188+$ & 0.165 & 1.441 \\
\hline Creative self-efficacy & & & & & & & 0.068 & 1.331 \\
\hline $\begin{array}{l}\text { Leader creativity*Creative } \\
\text { self-efficacy }\end{array}$ & & & & & & & & $-0.238^{* *}$ \\
\hline $\mathrm{R}$ & 0.011 & 0.431 & 0.062 & 0.150 & & 0.173 & 0.177 & 0.246 \\
\hline$\Delta R 2$ & 0.011 & $0.431^{* *}$ & 0.062 & $0.087^{* *}$ & & $0.023+$ & 0.04 & $0.069^{*}$ \\
\hline
\end{tabular}

Note. $N=115$. Unstandardized regression coefficients and unadjusted values are reported ${ }^{*} p<.05,{ }^{* *} p<.01,+<.10$

In general, we passed Baron and Kenny's (1986) mediation process and provided support for Hypotheses 2.

\section{Creative self -efficacy as the moderator}

Hypothesis 3 suggests that team members' creative self-efficacy moderates the relationship between team creativity efficacy and $\mathrm{OCB}$, in such a way that the relationship would be weaker for those with high, as opposed to low, creative self-efficacy. As shown in Model 8 of Table 2, the interaction term between team creative efficacy and perceived creative self-efficacy is significant $(\gamma=-0.238, p<.05)$, which supports Hypothesis 3 . We then tested the simple slope and the result shows it is significant $(t=16.845, p<.01)$ (See Fig. 2).

However, to address common method bias, we calculated the condition index in the regression test. The condition index for the full model is 166, which suggests a severe multicollinearilty problem. Thus, we designed an experiment in Study 2 to increase internal validity.

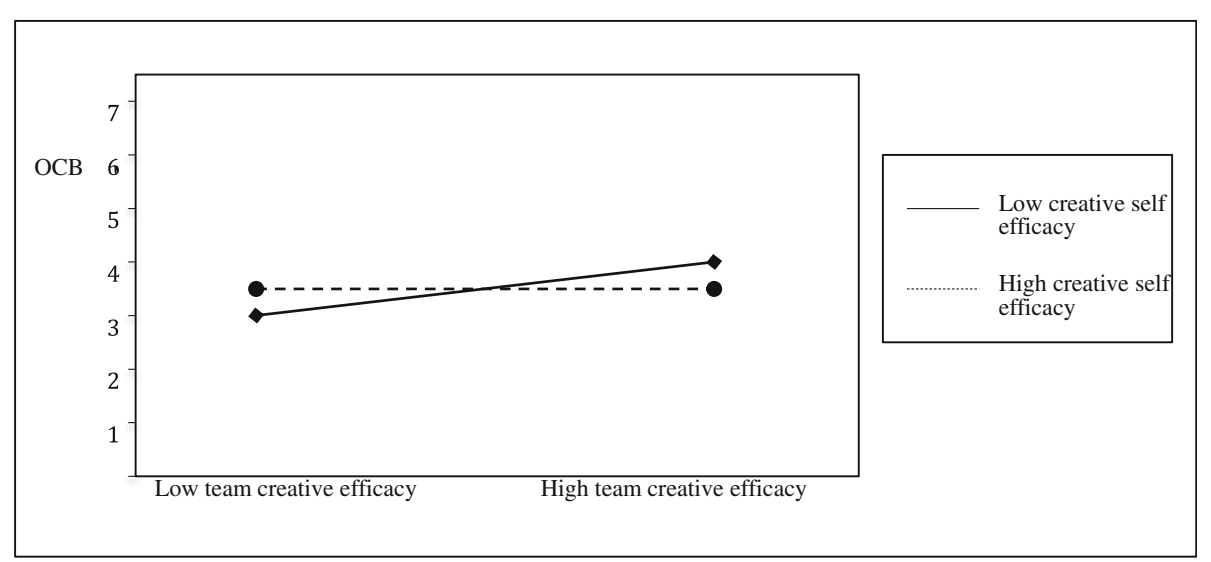

Fig. 2 *The Interacting Effect Between Team Creative Efficacy and Creative Self-Efficacy (Study 1) 


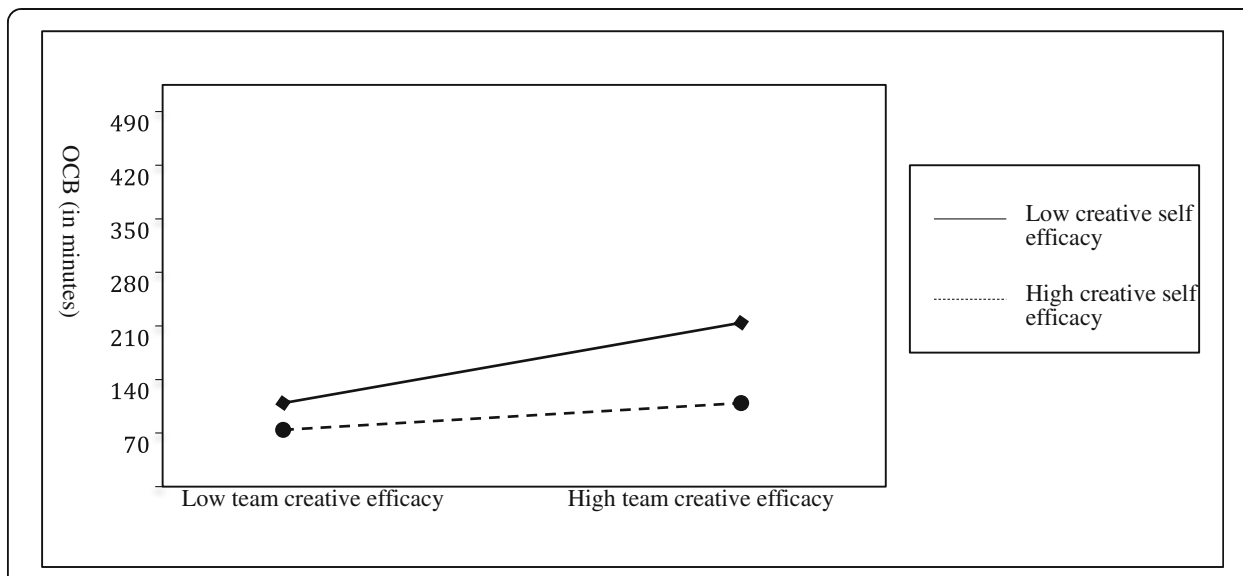

Fig. 3 *The Interacting Effect Between Team Creative Efficacy and Creative Self-Efficacy (Study 2)

\section{Study 2}

Method

Participants

We recruited 70 participants through Amazon MTurk (www.mturk.com) and paid them one US dollar for their time and effort. They were full-time employees working at least $35 \mathrm{~h}$ per week. Half of them were 25 to 34 years old and 54.3\% were male.

\section{Procedures}

This study consists of three parts: "Part 1: About You"- in this part we rated participants' creative self-efficacy; "Part 2: Past Work Experiences"- on page 1 of this part, in order to manipulate leader creativity, we asked participants to recall a leader with high/ low levels of creativity that they had worked with and to provide three examples in detail. Then on page 2, we asked participants to recall the team they worked in that was supervised by this leader and to rate the team creative efficacy; "Part 3: A New Work Situation"- In this part we invited participants to imagine they were working with the leader and the team identified in the previous section again but on a different task. They were told the company they worked for was going to hold a poster-design competition to celebrate its 15 th anniversary. Their team had $8 \mathrm{~h}(480 \mathrm{~min})$ to submit the poster design; however, there was a set of activities that needed to be followed for the work to be completed. Participants were asked decide how they would allocate their time among these activities.

\section{Measures}

Leader creativity manipulation We manipulated leader creativity by asking participants to recall the most creative leader (a condition of high leader creativity) or the least creative leader (a condition of low leader creativity) they had worked with throughout their career. In order to facilitate recalling and engage participants in the task, we asked them to write down (a) the initials of the leader, (b) the age of the leader when they worked with him or her, and (c) how long they worked together. Then they were asked to give three examples describing in detail what made them think the leader was highly creative or not creative. 
Creative self-efficacy This variable was measured with the scale used in Study 1. Cronbach's alpha was 0.89 .

Team creative efficacy This variable was measured with the scale used in Study 1 . Cronbach's alpha was 0.97 .

OCB OCB was measured with the total amount of time (in minutes) that participants allocated to the seven activities on OCB, which were embedded in the list of eighteen activities. The seven OCB activities were adopted from the 7-item OCB scale developed by Van Dyne and LePine (1998).

\section{Results}

The descriptive statistics and correlations among dependent variables and independent variables are displayed in Table 3. From the descriptive statistics, we can see the mean and standard deviation of all the variables and the correlation between them.

\section{Leader creativity and $O C B$}

We first conducted an analysis of variance (ANOVA) on OCB with leader creativity as a between-subjects independent variable. The effect of leader creativity on OCB is significant, $\left(F(1,67)=21.16, p<.01\right.$, partial $\left.\eta^{2}=.24\right)$, suggesting that OCB is higher under the conditions of high leader creativity $(M=191.71$, $S D=91.06)$ than when there is low leader creativity $(M=115.43, S D=36.52)$. Hence, Hypothesis 1 is supported.

\section{Team creative efficacy as the mediator}

To test the mediating effect of team creative efficacy on the relationship between leader creativity and $\mathrm{OCB}$, we conducted stepwise regressions by following the procedures set forth by Baron and Kenny (1986). First, leader creativity shows a significant, positive effect on OCB $(\beta=0.49, p<.01)$, suggesting that participants in teams with high leader creativity tend to allocate more time to OCB activities than participants in teams with low leader creativity. Next, leader creativity shows a significant, positive effect on team creative efficacy $(\beta=0.70, p<.01)$, suggesting that participants in teams with high leader creativity perceive their team's creativity efficacy to be higher than participants in teams with low leader creativity. When both leader creativity and team creative efficacy were entered in the regression, the effect of leader creativity was still significant but the coefficient became smaller $(\beta=0.32, p<.05)$, Meanwhile, the effect of team creativity efficacy was not significant $(\beta=0.24, p>.1)$. Thus, Hypothesis 2 is not supported.

Table 3 *Means, standard deviations, and intercorrelations of variables in Study 2

\begin{tabular}{llllll}
\hline Variable & Mean & SD & 1 & 2 & 3 \\
\hline 1. Leader creativity & 0.5 & 0.504 & & & \\
2. Team creative efficacy & 4.333 & 1.401 & $0.365^{* *}$ & & \\
3. Creative self-efficacy & 4.957 & 0.906 & $0.704^{* *}$ & $0.434^{* *}$ & \\
4. OCB & 153.57 & 78.86 & $0.487^{* *}$ & 0.067 & $0.463^{* *}$ \\
\hline
\end{tabular}

Note: $N=70 .{ }^{*} p<.05,{ }^{*} p<.01,+<.1$ 


\section{Creative self-efficacy as the moderator}

To test the moderated mediation proposed in Hypothesis 3, we applied the PROCESS macro developed by Hayes and Preach (2010) in SPSS, using Model 14 with 5000 bootstrapping iterations. The result shows the moderated mediation effect is significant (95\% confidence interval: $[-42.13,-1.89]$ ), which supports Hypothesis 3 . We then conducted a simple slope test and the results show it is significant $(t=852.7, p<.01)$. Please see Fig. 3 for the graph of the interaction effect.

\section{Discussion}

The results of our research suggest that subordinates of creative leaders are inclined to engage in $\mathrm{OCB}$ and that team creative efficacy mediates the relationship between leader creativity and $O C B$ in that subordinates of creative leaders tend to perceive team creative efficacy to be high, which drives them to engage in OCB to support the team and colleagues. As well, subordinate creative self-efficacy moderates the relationship between team creative efficacy and subordinate OCB in such a way that when team creative efficacy is high, subordinates who perceive that their creative self-efficacy is low are more willing to practice OCB.

Our research contributes to the literature by integrating and extending the findings of past studies. First, moving beyond prior leader creativity research that has been overwhelmingly focused on the influence on subordinates' creativity, we take leaders as the principle agent of the team and apply social cognitive theory to elucidate a more complete range of effects. Interestingly, our results reveal that the leader's creativity can also impact subordinates' OCB. Second, our study provides an initial step toward unpacking the underlying mechanisms associated with a leader's creativity and subordinates' OCB. In an attempt to examine the issue from the perspective of the subordinates, we tested the mediating role of team creative efficacy. As expected, the leader's creativity predicted the team's creative efficacy, such that subordinates would perform more OCB. This study adds to a growing body of literature showing how leaders' creativity is perceived by their subordinates and how leaders' creativity can disproportionately influence subordinates' choice to engage in OCB. Third, we find subordinates' creative self-efficacy can act as the moderator of leader creativity and subordinate OCB. For those with low creative self-efficacy, leader creativity have more impact on $\mathrm{OCB}$, since they have limited ways to contribute to achieving the team goals. This finding helps us acknowledge individual differences in contributing to achieving team goals.

\section{Implications}

Our findings have implications for practice as well. As noted before, leader creativity is garnering more interest in recent years, especially in creative enterprises. This study shows that selecting creative leaders can bring more benefits, such as more engaged and supportive subordinates, than just promoting positive change. Here, our data suggests that the more creative the leader is, the more subordinates will engage in OCB.

Another implication this study has for practice is that employees who are not confident about their creativity are still valuable to organizations. Nowadays, many leaders, especially those in high-tech companies, will encourage employees to be 
more confident to 'think out of the box'. However, this study demonstrates that unconfident employees who support and contribute to the team also have a unique value to the team.

\section{Limitations and suggestions for future research}

Our research also has several limitations that need to be noted. With our discussion of these limitations, we simultaneously suggest directions for future studies. First, in Study 1 we use MBA and undergraduate students as participants. Although most of the participants have work experience and the class context is similar to the real workplace as well as highly related to creativity, they are still different from real working employees. Furthermore, because of the small sample size, data used in Study 1 also suffered a severe multicollinearilty problem. For future research, collecting data with a larger sample size from teams in real working contexts is necessary to confirm the hypotheses put forward in this paper.

For Study 2, we asked the participants to recall the most creative or least creative leaders they had worked with. However, memory can be biased, thus making participants' choices different from what they would do in real working teams. For future research, it would be better to invite participants to labs and assign them to different groups. Then we can observe how participants behave under high/low leader creativity conditions.

The final limitation of our research is that our model focuses on the impact of subordinates' cognitive processes and leaders' traits on OCB, but does not take job characteristics and organizational characteristics into consideration. However, these two factors have been shown to be related to subordinate OCB in previous research (Podsakoff et al., 2000). An interesting direction for future research would be to examine how these four factors interact with each other to influence the relationship between leader creativity and subordinate OCB.

Funding

None.

Authors contributions

XD participated in the design of the study and performed the statistical analysis, and helped to draft the manuscript. ZG participated in the design of study and carried out experiments, and also drafted the manuscript. Both authors read and approved the final manuscript.

Competing interests

The authors declare that they have no competing interests.

\section{Publisher's Note}

Springer Nature remains neutral with regard to jurisdictional claims in published maps and institutional affiliations.

Received: 1 August 2017 Accepted: 19 September 2017

Published online: 30 September 2017

References

Aiken, L. S., West, S. G., \& Reno, R. R. (1991). Multiple regression: testing and interpreting interactions. Newbury Park, Calif: Sage Publications.

Amabile, T. M. (1983). The social psychology of creativity: A componential conceptualization. Journal of Personality and Social Psychology, 45(2), 357-376.

Amabile, T. M. 1988. From Individual Creativity to Organizational Innovation: 139-166.

Badawy, R. L., Shaughnessy, B. A., Brouer, R. L., \& Seitz, S. R. (2016). Are you actually helping or just looking out for yourself?: examining the individual and interactive effects of relationship quality and political skill on supervisor motive attributions. Organization Management Journal, 13(3), 124-137.

Bandura, A. (1986). Social foundations of thought and action: A social cognitive theory. New Jersey: Prentice-Hall, Inc. 
Bandura, A. (1989). Human agency in social cognitive theory. American Psychologist, 44(9), 1175.

Bandura, A. (1997). Self-efficacy: the exercise of control. New York: W.H. Freeman.

Bandura, A. (2001). Social cognitive theory: An agentic perspective. Annual Review of Psychology, 52(1), 1-26.

Baron, R. M., \& Kenny, D. A. (1986). The Moderator-Mediator Variable Distinction in Social Psychological Research: Conceptual, Strategic, and Statistical Considerations. Journal of Personality and Social Psychology, 51(6), 1173-1182.

Bateman, T. S., \& Organ, D. W. (1983). Job Satisfaction and the Good Soldier: The Relationship Between Affect and Employee "Citizenship". Academy of Management Journal, 26(4), 587.

Beauregard, T. A. (2012). Perfectionism, self-efficacy and ocb: the moderating role of gender. Personnel Review, 41(5), 590-608.

Brislin, R. W. (1986). In W. J. Lonner \& J. W. Berry (Eds.), The wording and translation of research instruments (pp. 71-101).

Britt, T. W., Mckibben, E. S., Greene-Shortridge, T. M., Odle-Dusseau, H. N., \& Herleman, H. A. (2012). Self-engagement moderates the mediated relationship between organizational constraints and organizational citizenship behaviors via rated leadership. Journal of Applied Social Psychology, 42(8), 1830-1846.

Collins, B. J., \& Mossholder, K. W. (2017). Fairness means more to some than others: Interactional fairness, job embeddedness, and discretionary work behaviors. Journal of Management, 43(2), 293-318.

Eby, L. T., Butts, M. M., Hoffman, B. J., \& Sauer, J. B. (2015). Cross-lagged relations between mentoring received from supervisors and employee ocbs: disentangling causal direction and identifying boundary conditions. Journal of Applied Psychology, 100(4), 1275.

Gonzalez-Mulé, E., Mount, M. K., \& Oh, I. S. (2014). A meta-analysis of the relationship between general mental ability and non-task performance. Academy of Management Annual Meeting Proceedings, 99(6), 1222-1243.

Hayes, A. F., \& Preacher, K. J. (2010). Quantifying and testing indirect effects in simple mediation models when the constituent paths are nonlinear. Multivariate Behavioral Research, 45(4), 627-660.

Huang, L., Krasikova, D. V., \& Liu, D. (2016). I can do it, so can you: the role of leader creative self-efficacy in facilitating follower creativity. Organizational Behavior \& Human Decision Processes, 132, 49-62.

Kern.F. 2010. What chief executives really want. Bloomberg Business Week

Koning, L. F., \& Kleef, G. A. V. (2015). How leaders' emotional displays shape followers' organizational citizenship behavior it? Leadership Quarterly, 26(4), 489-501.

Lam, C. F., Liang, J., Ashford, S. J., \& Lee, C. (2015). Job insecurity and organizational citizenship behavior: exploring curvilinear and moderated relationships. Journal of Applied Psychology, 100(2), 499

Lev, S., \& Koslowsky, M. (2012). Teacher gender as a moderator of the on-the-job embeddedness-ocb relationship 1. Journal of Applied Social Psychology, 42(1), 81-99.

Matta, F. K., Scott, B. A., Koopman, J., \& Conlon, D. E. (2015). Does seeing "eye to eye" affect work engagement and organizational citizenship behavior? A role theory perspective on LMX agreement. Academy of Management Journal, 58(6), 1686-1708.

Mueller, J. S., Goncalo, J. A., \& Kamdar, D. (2011). Recognizing creative leadership: Can creative idea expression negatively relate to perceptions of leadership potential? Journal of Experimental Social Psychology, 47(2), 494-498.

Niehoff, B. P., \& Moorman, R. H. (1993). Justice as a mediator of the relationship between methods of monitoring and organizational citizenship behavior. Academy of Management Journal, 36(3), 527-556.

Podsakoff, P. M., MacKenzie, S. B., Paine, J. B., \& Bachrach, D. G. (2000). Organizational Citizenship Behaviors: A Critical Review of the Theoretical and Empirical Literature and Suggestions for Future Research. Journal of Management, 26(3), 513-563.

Shin, S. J., \& Zhou, J. (2007). When is educational specialization heterogeneity related to creativity in research and development teams? Transformational leadership as a moderator. Journal of Applied Psychology, 92(6), 1709.

Tierney, P., \& Farmer, S. M. (2002). Creative Self-Efficacy: Its Potential Antecedents and Relationship to Creative Performance. The Academy of Management Journal, 45(6), 1137-1148.

Van Dyne, L., \& LePine, J. A. (1998). Helping and voice extra-role behaviors: Evidence of construct and predictive validity. Academy of Management Journal, 41(1), 108-119.

Williams, L. J., \& Anderson, S. E. (1991). Job Satisfaction and Organizational Commitment as Predictors of Organizational Citizenship and In-Role Behaviors. Journal of Management, 17(3), 601.

Zhou, J., \& George, J. M. (2001). When Job Dissatisfaction Leads to Creativity: Encouraging the Expression of Voice. The Academy of Management Journal, 44(4), 682-696.

\section{Submit your manuscript to a SpringerOpen ${ }^{\circ}$ journal and benefit from:}

- Convenient online submission

- Rigorous peer review

Open access: articles freely available online

- High visibility within the field

- Retaining the copyright to your article

Submit your next manuscript at $\gg$ springeropen.com 